\title{
Using De Bono's Six Thinking Hats Model to Teach Critical Thinking and Problem Solving Skills Essential for Success in the 21st Century Economy
}

\author{
Charles Kivunja \\ School of Education, The University of New England, Armidale, Australia \\ Email: ckivunja@une.edu.au
}

Received 22 February 2015; accepted 12 March 2015; published 17 March 2015

Copyright (C) 2015 by author and Scientific Research Publishing Inc.

This work is licensed under the Creative Commons Attribution International License (CC BY).

http://creativecommons.org/licenses/by/4.0/

$$
\text { (c) (i) }
$$

\begin{abstract}
It is understood that although critical thinking and problem solving are recognized as skills that are essential for success, particularly in the 21st century Digital Economy, they are not explicitly taught as part of the curriculum in many educational institutions. To make a contribution to an understanding of how critical thinking and problem solving can be taught effectively, the present paper draws upon the work of one of the leaders in critical thinking and problem solving to illustrate how these skills could be taught using De Bono's Six Thinking Hats Model. Following an exposition of the key tenets of De Bono's Model, the paper discusses how each of the Six Thinking Hats could be used in an effective pedagogy.
\end{abstract}

Keywords

Attributes of Critical Thinking, Critical Thinking, De Bono's Six Thinkng Hats, Key Pedagogical Tenets, Problem Solving

\section{Introduction}

As Pohl (1997) clearly points out, if students are to learn critical thinking skills, they must be explicitly taught these skills. Likewise, one of the world's leading experts on teaching critical thinking skills says that his "experience suggests that thinking skills are most effectively taught if they are taught directly and deliberately” (De Bono, 1992c: p. 7). Unfortunately this is often not the case as can be seen in many curriculum documents of many educational institutions. For example, even in the highly developed educational systems such as the USA, 
studies by Trilling and Fadel (2009) found that students graduating at all levels, including schools and universities, lacked critical thinking and problem solving skills. It is therefore helpful to pedagogical practice to discuss how critical thinking and problem solving skills can be taught effectively.

When it comes to consideration of direct teaching of thinking as an effective pedagogical strategy, Dr. Edward de Bono (1956; 1985; 1992a; 1992b; 1992c; 1992d; 1995) is in a league of his own as a leader in this field. This is perhaps best illustrated by the fact that he won the prestigious award as key pioneer in the explicit teaching of thinking at the International Thinking Meeting in Boston in 1992. Having developed the concept of lateral thinking, Dr. de Bono's work on how people think has been published in numerous books which have been translated into many languages. His programs for the teaching of thinking have proven very popular for use in many countries across the globe including Argentina, Venezuela, the USA, Canada, Singapore, Australia and New Zealand. Furthermore, having held professorial positions at top universities in the world including Oxford, London, Cambridge and Harvard University, Dr. de Bono clearly deserves the kudos of being a leading scholar in critical thinking and problem solving and is recognized and highly regarded by his peers in the profession at an international level. That's why utilizing De Bono's Six Thinking Hats Model is well justified. So it is helpful to explore his Six Hats Thinking Model and to discuss how it can be used to teach critical thinking and problem solving. But first, let's briefly have a look at what critical thinking is, what it involves and why it is essential for success in the 21st century, and then discuss how we can teach it using De Bono's Model.

\section{Critical Thinking, Its Attributes and Why It Is an Essential Skill for Success in the 21st Century Economy}

\subsection{The Meaning of Critical Thinking}

Several scholars including Carmichael (1997), Dobozy, Bryer and Smith (2012) and Mulnix (2010), have defined critical thinking in different ways but one that appears to capture its meaning very well is provided by The National Council for Excellence in Critical Thinking, based in California, which states it as: "the intellectually disciplined process of actively and skillfully conceptualizing, applying, analyzing, synthesizing, and/or evaluating information gathered from, or generated by, observation, experience, reflection, reasoning, or communication, as a guide to belief and action” (NCECT, 2014: p. 2). Likewise Kivunja (2015a) says "critical thinking is the cognitive process that creates the ability to interpret, analyze and evaluate information, arguments or experiences with a set of reflective attitudes, skills and abilities to guide our thoughts, beliefs and actions” (p. 431). These definitions serve to underline that critical thinking is a skill that is essential in putting across a point, or proving a point, evaluating and interpreting the meaning of views or ideas expressed, and applying what has been learnt to solve new problems. Critical thinking and problem solving are mutually interdependent because, as explained by Reynolds (2012) the practical value of critical thinking skills is the application of those skills to solve problems that enable rational decisions to be made to enhance successful human activities. Thus, these two sets of skills are essential for daily living and productive citizenship.

\subsection{Attributes of Critical Thinking}

Arguing that critical thinking and problem solving are essential for humans to live as civil society, and utilizing the example of courtroom procedures to illustrate what it involves Facione (2011), says it involves the use of reasons to convince others about an issue, such as a lawyer trying to convince the judge and the jury of the client's claim, identifying relevant evidence and evaluating its significance, interpreting what is said, analyzing and evaluating the arguments presented by others. From Facione's (2011) example drawn from a typical courtroom procedure we can infer many attributes that critical thinking and problem solving involve. They include keeping an open-mind as one listens to points put forward, keenly observing what is said and noting any gaps in it, thinking deeply and consciously raising questions, distinguishing between observation and inference, and between fact and conjecture (Esterle \& Cluman, 1993). Furthermore, it involves drawing inferences from what is said, probing for underlying assumptions, and developing hypotheses which can be investigated to clarify issues. It involves engaging in inductive or deductive reasoning, to gain an understanding of what data really mean as well as identification and avoidance of prejudice (Miller, 1990). Comprehensive critical thinking and problem solving help in the determination of what is valid or not, fact or fiction, real or hype, relevant or nonsense and testing one's own line of reasoning, decision making, and problem solving against those of others 
(Le Cornu, 2009). Thus these skills provide for objectivity, honesty, empathy, exploring, explaining, elaborating, applying, analyzing, sequencing, comparing, evaluating, appraising, creating and self-regulation, all of which are essential for harmonious cohabitation by humans.

\section{Exploring the Key Pedagogical Tenets of De Bono's Six Thinking Hats Model}

Using the metaphor of wearing different coloured hats, De Bono has designed a very simple model but one which when applied correctly can immensely augment critical thinking and create opportunities for solving any problems that might be confronted. The model reflects De Bono's belief that "simple methods used effectively are more valuable than complicated methods that are difficult to understand and confusing to use" (De Bono, 1992c: p. 6). In explaining the philosophical underpinnings of his six coloured hats thinking model De Bono (1992d) says that "when we attempt practical thinking, there are three fundamental difficulties" (p. 8) that we encounter. He identifies those difficulties and explains them as follows:

1) Emotions. We often have a tendency not to think at all but to rely on instant gut feeling, emotion and prejudice as a basis for action.

2) Helplessness. We may react with feelings of inadequacy: "I don't know how to think about this. I don't know what to do next".

3) Confusion. We try to keep everything in mind at once, with a mess as a result (De Bono, 1992d: p. 8).

So, how does De Bono's metaphor of wearing the six different thinking hats enable us to overcome these three difficulties? The mighty power of De Bono's coloured hats metaphor in addressing these difficulties lies in the ability of the hat wearer to take off one coloured hat once they have finished with it and wear another one. The wearing of a different coloured hat enables the wearer to bring a different perspective to thinking critically about an issue and to trying to find alternative solutions to any problem confronted. Arguing that "Emotions at the right place in thinking are essential [but] emotions at the wrong place can be disastrous, [De Bono, 1992 says that] the six hats method allows us to use emotions and feelings at the right place” (p. 8). Arguing that helplessness arises when we don't have a clear plan of action to take when confronted with a problem, De Bono (1992c) suggests that the wearing of different coloured hats "provides us with a basic framework for thinking actions, [in the form of] definite next steps that can be taken” (p. 8) to solve the problem. And as for the third problem, De Bono (1992c) says that "confusion arises when we try to do too much at once [but] the six hats method allows us to take one direction at a time" (p. 8).

The six thinking hats metaphor represents six different cognitive approaches to critical thinking and analysis to understand an issue or problem and trying to come up with an appropriate resolution. In the metaphor, the six hats are coloured Black, Blue, Green Red, White, and Yellow, and each coloured hat represents a different logical and philosophical approach to critical thinking about a problem and trying to solve it. Figure 1, uses hat images sourced from: https://www.google.com.au/search?q=images+of+hat to summarize the conceptual thinking associated with each hat. De Bono (1992d) says that "the six hats method allows students to think more richly and more comprehensively" (p. 15).

As already said and now illustrated in Figure 1, De Bono's model comprises six different coloured hats. Each hat represents a different way of dealing with critical thinking about how to approach and solve a problem. As summarized in Figure 1, the black hat is for caution in critical thinking. De Bono chose the colour black for the cautious critical thinking perspective because the word critical has its origin in Greek where it means judge. De Bono (1992c) explains that in many countries judges wear black and so the colour black is appropriate for this way of thinking because it represents a serious consideration of issues or problems to solve. The issues involve questioning the feasibility of alternative approaches to problem solving, assessment of issues at hand, identifying what's wrong, looking for weaknesses in an argument or proposal and evaluating issues so as to be able to pass judgment.

Although the black hat is associated with thinking that questions and checks the feasibility and validity of proposals and seeks to evaluate and pass judgment, it does not represent adversarial or undesirable thinking. It is not a bad hat. De Bono (1992b) says, "With the black hat, the words checking and checking out are very important to explaining its uses. These words convey the essence of critical thinking - and do not carry a negative image” (p. 31). It informs critical thinking by providing for caution so that well thought out strategies can be designed to solve the problem. Critical thinking and problem solving while wearing the black hat creates opportunity for assessing the possible consequences of our decisions and can save us the costs of implementing unworkable strategies or embarking upon disastrous courses of action. 


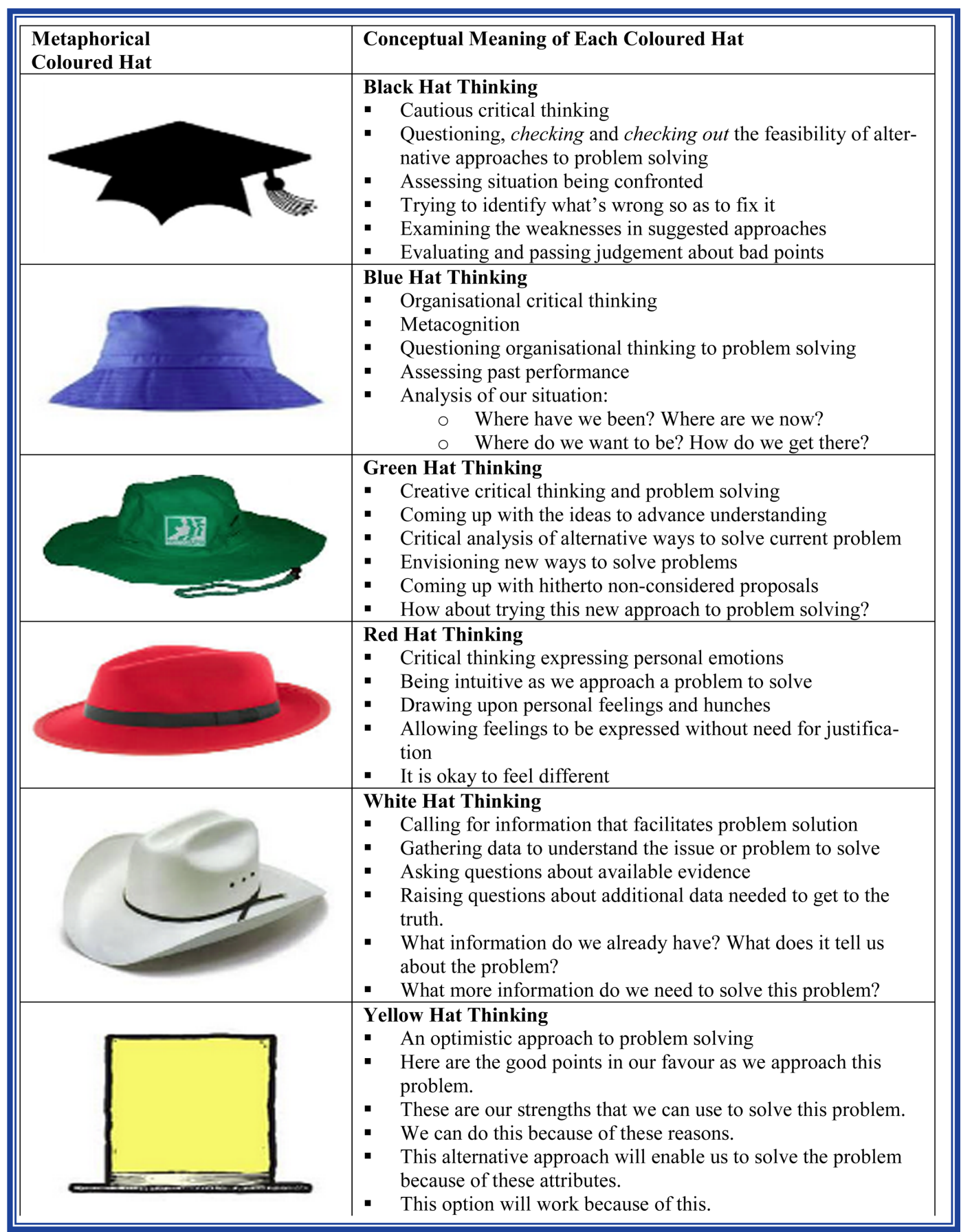

Figure 1. A synthesis of De Bono's six thinking hats model.

As illustrated in Figure 1, wearing the blue hat brings the perspective of organizational critical thinking and metacognition. This makes blue hat thinking different from all the other hats because while the other hats are concerned with thinking about how to solve a particular problem, blue hat thinking is focused on thinking about thinking that will lead to a solution. Thus, blue hat thinking brings to the critical thinking and problem solving process, higher order thinking which involves active control over the cognitive processes engaged in seeking for a reasonable solution to a problem. It helps to identify strategies and to plan activities that can be implemented to solve a given problem. Because the blue hat thinking is a higher order thinking hat, De Bono justifies its colour as follows: 
We can associate the blue hat with the blue sky which is above everything. If we were up in the sky, we could look down and see what was happening on the ground below. With the blue hat, we try to rise above the thinking that is taking place and to get an overview of this thinking. With the blue hat we try to take charge of our thinking in order to organize what is going on. (De Bono, 1992b: p. 102)

Thus, blue hat think brings a special perspective to critical thinking and problem solving which helps to define and articulate the nature of the problem, set clear objectives or targets to be pursued in solving that problem, identify alternative steps to be taken in the pursuit of the solution, assess and re-assess progress being made, and continually decide on the next steps as movement takes place towards the planned outcome.

With reference to Figure 1, we can see that the green hat is for creative critical thinking and problem solving. De Bono (1992d) explains the essence of the green hat perspective when he says:

We can look at the word creative in two ways. The first way means "generating, producing, creating something which was not there". The second way means "having new ideas, fresh ideas and ideas that have not been used before". (p. 72)

In justifying the colour green for this hat, De Bono (1992) says that the colour green conjures up images of nature and vegetation and so green can easily symbolize the productive capacity and energy bound in the natural resources. It brings to the critical thinking and problem solving process new ideas, new possibilities, suggestions and proposals not offered before. So it represents thinking creatively and innovatively. "This means moving forward to possibilities and new ideas" (De Bono, 1992b: p. 72).

From Figure 1 we can see that the red hat brings to the critical thinking and problem solving process opportunities to express personal emotions. These are expressed without fear of being judged and with no need for justification. Emotions, feelings, hunches and intuitive ideas are shared in a context of freedom of expression. Participants are free to say how they feel about an approach being taken in attempts to solve a problem, at a particular moment in time, without having to provide an explanation, or giving reasons for their feelings. As there is freedom of expression and no need for justification, participants are free to express their feelings without having to look for logic and rationalization for those feelings. Thus, this hat creates opportunities for participants to be humanly real, not always having to be objective and free to hold on to what they value and think, without fear that they will be challenged.

De Bono justifies the use of the colour red for this hat saying, "Think of the redness of fire. Think of anger and joy but also of warmth and contentment. The red hat includes both intense and more gentle feelings" (De Bono, 1992c: p. 87). As illustrated in Figure 1, under the red hat lie emotions, feelings, hunches, and intuitions. The emotions brought to the thinking process with this hat include joy, fear, anger, jealousy and sorrow. Feelings are broader than emotions and they include likes, dislikes, anxiety, uncertainty, interest, exciting, aesthetics, respect and camaraderie. Intuitions are even broader than feelings and they surface when one acts instinctively without subjecting their actions to rationalization. They might be logical but they involve no deliberate cognitive processing and their probabilities are unknown. Essentially, red hat thinking helps to answer the question "What do I feel about this?” (De Bono, 1992c: p. 90).

As illustrated in Figure 1, white hat thinking brings to the critical thinking and problem solving process requests for information that is needed to help solve the problem at hand. Its focus is on three questions, "what information do we have? and to increase the information base, what information do we need? [and] how do we get the information we need" (De Bono, 1992b: pp. 57-58). And having identified the information needed, the white hat thinking provides for going out to collect that information. This perspective involves personal as well as group searches for information.

De Bono aligns this type of thinking with the metaphor of a white hat because he associates information with a typical typed report which provides information on white paper. He also alludes to information in computer printouts which are conventionally produced on white paper. Another association that De Bono associates with the colour for this hat is information in newspapers which is again conventionally printed on white paper. He extends his justification for associating the colour white to information by suggesting that the whiteness signifies neutrality and objectivity of the information sought while wearing this hat because all that this hat seeks is "just information, with no suggestions, ideas or arguments. Feelings do not come into it. [It says] never mind the arguments. What is the information here?” (De Bono, 1992b: p. 57). Consideration is of course given to the relevance of the information and to its source to determine its integrity, importance and validity. When we wear the white hat it brings to us a proactive urge to deliberately go out and look for data so that we become well 
informed members of society rather than wait for a problem and then look for information on how it might be solved.

As summarized in Figure 1, yellow hat thinking brings to the critical thinking and problem solving process a sense of optimism and determination to succeed. It looks for the strengths that we have and the opportunities that the situation presents to us. It seeks to draw upon present strengths and successes to advance to new heights of success. Current success fuels courage for further success. With this hat, alternative options that can lead to improved performance are identified. De Bono (1992b) says it involves looking for four aspects "(1) good points, (2) benefits (3) reasons why an idea will work, (4) likelihood of success” (p. 44).

De Bono (1992c) associates this optimistic approach to problem solving to the colour yellow because he says "Yellow can mean sunshine and optimism and looking on the bright side of things" (p. 43). This optimism is based on supporting evidence and is not just fantasy or mere wishes driven by emotions. This makes a big difference between the emotions brought to the critical thinking and problem solving process under red hat thinking and the optimistic approach which not only wishes for great things to happen but also analyses the benefits that can flow from those good things and why the actions taken would lead to improved results. With the yellow hat, "A suggestion is made, a solution is offered, a plan is put forward. The benefits that are claimed for each of these are going to come in the future. ...we must have good reasons for claiming that these benefits will come through” (De Bono, 1992d: p. 43).

\section{How to Use De Bono's Six Thinking Hats Model to Teach Critical Thinking and Problem Solving Skills}

Now that we have an understanding of the approach to critical thinking and problem solving associated with each of De Bono's Six Thinking Hats Model, let's have a look at how this model can be used to explicitly teach critical thinking and problem solving.

\subsection{Applying Black Hat Thinking Strategies}

In consideration of the thinking perspective that wearing the black hat means as explained above and illustrated in Figure 1, students can be taught critical thinking and problem solving under this hat by giving them activities which require them to provide evidence that substantiates what they say. The following ten questions are a good way to design and implement activities that teach students black hat critical thinking and problem solving.

1) What is the evidence?

2) Is what we are proposing fair?

3) What is the logic behind what is being proposed?

4) Is it feasible?

5) Why might this plan not work?

6) Is this proposal or approach reasonable in terms of the learning outcomes we are seeking to achieve?

7) What might go wrong if we proceed that way?

8) What are the weaknesses in this strategy?

9) What threats shall we face?

10) What consequences will flow from these actions?

De Bono suggests that in teaching critical thinking and problem solving with the black hat, we should ask students to check for evidence that supports what they say. They should check for truth or validity of logical arguments raised within their study groups. They should examine suggestions made to see if they are feasible, given the prevailing circumstances. They should think deeply about the possible consequences of their actions before making related decisions, and in particular "The most important part of checking the impact of an idea is the effect it may have on values. [So students should ask] how does the idea affect others' values?” (De Bono, 1992b: p. 31).

\subsection{Applying Blue Hat Thinking Strategies}

In consideration of the thinking perspectives associated with the blue hat as shown in Figure 1 and explained above, De Bono (1992c) suggests that blue hat thinking, "is most often used at the beginning, in the middle and at the end of a thinking session” (p. 102). Thus, in a normal lesson plan, blue hat thinking can be used in the introduction, body of the lesson and in the conclusion to the lesson. So, it gives students opportunities to apply it 
across all parts of a lesson.

Kivunja (2015a: p. 34) recommends the following ten strategies to help students develop critical thinking and problem solving skills applying the blue hat:

1) Before you start, define the purpose of what you are planning to do.

2) Here are some alternative views to start exploring this idea. Start with them and develop your thinking further.

3) Can you explain how you reached that conclusion?

4) What are we trying to achieve and how shall we get there?

5) What learning outcomes should we aim for and how shall we achieve them?

6) How about examining each of these steps and considering its implications?

7) What have we got so far?

8) What plan or strategy would enable us to complete this activity successfully?

9) In organizing a menu for a party that will include vegetarians, what thinking steps would you use to complete this task?

10) Clearly define your learning expectations of this lesson or activity.

De Bono recommends that to teach students critical thinking and problem solving while wearing the blue hat, they should be told that "If we are going somewhere, it is useful to know where we are trying to go. The blue hat defines the problem or task and the purpose of the thinking. The blue hat lays out the situation" (De Bono, 1992d: p. 102). Emphasizing that critical thinking using the blue hat should be constructive, De Bono suggests that learners being taught to use this hat should be asked to restate their original thinking so that they keep focused, redefine the task if they see that changes need to be made and set up a structure of thinking steps that they should follow as they try to solve a problem or complete the assigned task. From time to time, students should be asked "to stand back from thinking in order to comment upon their own thinking” (De Bono, 1992b: p. 103).

\subsection{Applying Green Hat Thinking Strategies}

As the green hat thinking brings the creativity and innovation perspective to critical thinking and problem solving, De Bono suggests that four types of activities that can be used to teach students how to use this hat are:

1) Generating reactive ideas

2) Generating starting ideas

3) Generating further and better ideas, [and],

4) Generating new ideas (De Bono, 1992b: p. 74).

In applying De Bono's suggestion of getting students to engage in generating reactive ideas to teach them critical thinking, I ask them to design another very simple model also designed by De Bono (1982) which is called the PMI model. It is called the PMI model because it asks students to think critically about an issue or idea and identify what they regard as "plus points in it, minus points and interesting points" (De Bono, 1982: p. 5). As students try to think of what is a plus or minus or interesting (PMI) idea, they engage in creative thinking as they explore different dimensions of the topic or idea being discussed. Asking students to use the green thinking hat reactively also gives them training in creative thinking as they are challenged to come up with new ideas to modify or improve upon what is said.

A strategy that is very effective in teaching students critical thinking through generating starting ideas is what is often referred to in pedagogy as the brain-storming strategy (Killen, 2013; Petty, 2009). Using this strategy, students are given only a hint as a starting idea which they then use to develop their thinking and volunteer their own ideas to be added to the pool of ideas contributed by the whole class.

A strategy that is quite helpful in generating further and better ideas is getting students to develop what is called a Concept Map (Pohl, 1997). The Concept Map is a kind of graphic organizer which students can use to generate further and better ideas relating to what has already been given. Using this structure students are encouraged to extend creative thinking to come up with something new or better ideas that they can add to the Concept Map. Thus this strategy can also be a very effective way of engaging learners in critical thinking through De Bono’s fourth type of activities for “generating new ideas” (De Bono, 1992b: p. 74).

\subsection{Applying Red Hat Thinking Strategies}

As explained and illustrated above, wearing the red hat brings to critical thinking and problem solving the 
opportunity for the wearers to formally express their emotions, feelings, hunches and intuition. To train students in how to use this hat, they can, for instance, be asked to say what they like or dislike about an idea. The following ten questions give students the opportunity to practice critical thinking and problem solving under this hat:

1) What are your feelings about this issue?

2) Can you tell the class what you don't like about this character?

3) How certain are you that this is an accurate account of what happened?

4) What do you find interesting about this?

5) What do you regard as the exciting aspects of this story?

6) Which parts of this activity did you find boring?

7) Why do you have preference of A over B?

8) What choices would you like to make?

9) What is your assessment of this act?

10) Which course of action would you like to take?

Questions such as these can be used to help students realize the main value of red hat thinking which De Bono (1992b) says, "is at the beginning of a discussion (to make feelings known) and at the end (assessment and choice)" (p. 90).

\subsection{Applying White Hat Thinking Strategies}

The emphasis in trying to teach students how to use white hat thinking in critical thinking and problem solving is on information that is needed to problem solve. If the information is available then it is mined, analyzed and used to inform critical thinking and to solve the problem being tackled. If it is not available, then critical thinking is undertaken to identify relevant sources for the needed information.

Training students in the use of this hat asks them to explain why the information they have found is relevant to the solution of the problem. It asks them to chunk the information into categories such as, of low value, important, very important. They are taught about validity of information (Hill, 1981) and how to assess whether the information they have is reliable (Cunningham, 1998) or not. So in teaching students how to engage in critical thinking it is helpful to also teach them some basic research methods techniques (Burns, 2000) such as the need not only to ensure that the information is valid and reliable but also that all data gathered need to be kept for some time so that it is available if further assessments of observations or results are called for. White hat wearers are taught how to identify and define gaps in data sets so they know what is missing and can therefore spend their time efficiently on gathering relevant data that are missing rather any data they come across. They have therefore to be trained in data gathering techniques such as different data sources, e.g. documents or internet or interviews; and if the data are to be gathered through interviews, which type of questions they should ask, how to interpret the answers and how to analyze the data and make sense of them. Seeking for answers to the following ten questions could help in the design of strategies that get white hat thinkers to engage in critical thinking and problem solving under this hat metaphor (Kivunja, 2015a):

1) What information do we have about this issue?

2) What information do we need?

3) Which questions should we ask to get relevant information?

4) Where does the information come from?

5) How shall we analyze and make sense of the data?

6) How reliable is the information?

7) How valid is the information?

8) Is the information relevant to our efforts to understand this concept or to solve this problem?

9) What other information might be helpful?

10) Do we have enough information?

\subsection{Applying Yellow Hat Thinking Strategies}

Teaching students to think critically and problem solve under the metaphor of the yellow hat is to get them to make a "deliberate effort to find benefits, ...to be able to pick out the good points even when there are very few or there are many more bad or dangerous points... [or when] the benefits may not be obvious" (De Bono, 1992c: p. 44). So students need to learn to be alert so they can detect circumstances which create opportunities for good 
outcomes to be experienced. They have to learn to recognize their strengths which they can utilize or exploit to achieve better results and to improve their performance. They need to recognize the factors within their context that they can control or influence so as to achieve a better result.

To engage in critical thinking and problem solving under the yellow hat, students should search for optimism which could come from simplifying the tasks they are given to complete. They should practice setting SMART objectives (Drucker, 1954). Peter Drucker uses the acronym SMART to refer to goals that are Simple, Measurable, Achievable, Realistic and Time-able. Setting SMART goals enhances optimism as it can lead to greater efficiency, as students don't spend a lot of time to achieve results and greater effectiveness when the students achieve the desired learning outcomes. Students should be taught that if they can come up with ideas that their peers accept as correct or as adding value to what they are doing or learning, this contributes to optimism in whatever they are learning or doing. They should look for new opportunities to accomplish what they are learning and try to employ personal learning strategies that facilitate their mastery of content and the skills being taught (Martinez \& Martinez, 1999).

Students learning to apply yellow hat thinking will benefit from activities that give them opportunities to assess the value of their activities, to identify the variety of benefits that could flow from what they are doing and through using their skills to make something work or to illuminate understanding. They may be helped along this trajectory by asking the following ten questions:

1) What good points can I summarize from this text?

2) What are the benefits to the group, class, school or wider community of that policy measure?

3) Why do you think that idea will help solve this problem?

4) What value do you see in this alternative course of action?

5) What is the likelihood that the resources or materials we have will suffice to complete the task satisfactorily?

6) What is the likelihood that this will be accomplished within the time allowed?

7) What contribution can I make to make this work?

8) What is the likelihood that we shall achieve these learning goals?

9) In what alternative ways can we improve our performance on this task?

10) If we could change the situation, what could we do to make the situation better?

\section{Conclusions and Pedagogical Implications of Applying De Bono's Model to Critical Thinking and Problem Solving}

Critical thinking and problem solving are not just important skills. They lie at the heart of Kivunja's (2014) "New Learning Paradigm" (p. 86), and they should be taught in every curriculum that seeks to prepare students for the challenges of the Digital Economy. They are "super skills" (Kivunja, 2015b: p. 4) essential for successful studies, work and living in the 21st century Knowledge Economy. It is vital that these skills be explicitly included in pedagogy otherwise students will finish school and graduate without them. This would be a tragedy because as pointed out by leaders in the field such as Dewey (1910; 1933), Facione (2011), and Larrivee (2008), they are essential for success in all walks of life. As Facione so cogently asserts:

There is hardly a time or a place where it would not seem to be of potential value. As long as people have purposes in mind and wish to judge how to accomplish them, as long as people wonder what is true and what is not, what to believe and what to reject, strong critical thinking is going to be necessary. (Facione, 2011: p. 10)

Tapscott (2009) and Trilling and Fadel (2009) also agree that these skills are essential for success not only at school, college and university, but also in life after studies. As Kivunja (2015a) admonishes "It is critical thinking skills that enable meaning to be made in all modes of thinking whether they are legal, commercial, political, psychological, philosophical or sociological” (p. 464). Thus critical thinking and problem solving are essential for life.

Given the convergence of expert opinion that critical thinking and problem solving are essential skills in all walks of life, it is regrettable that they do not occupy more dominant positions in the curriculum documents of many educational institutions. Whether this is due to some fallacious misconstruction that because all people think there is no need to teach thinking skills, or due to the realization that these skills are not easy to teach, the 
fact of the matter is that there is a pedagogical gap that needs to be filled. This is why it is important, and plausible, to employ a well-proven model, designed by a world-renown expert on critical thinking and problem solving (Maltese Dr. Edward de Bono) whose "critical thinking models are used worldwide” (De Bono, 1982: p. 5) to teach students how to think critically and how to solve problems.

As explored and demonstrated in this paper, De Bono's Six Thinking Hats model equips pedagogues with the opportunity to teach their students how to develop their critical thinking and problem solving skills by using a certain type of thinking and to stop using it when they have exhausted its utility and switch on to another type of thinking. The metaphor of "wearing a different coloured hat" serves to effectively dramatize the ease with which students can move from thinking critically about an issue from one perspective to another. For example, by wearing their black hat thinking students can assess the feasibility of alternative approaches to problem solving. They can then take it off and switch to the blue hat thinking to analyze how far they have advanced in trying to solve the problem. They can take the blue hat thinking off and wear the green hat thinking to come up with new and better ways of solving the problem. They can take off the green hat and switch to the red hat so that they express their likes and dislikes about the progress made so far. They can switch to the white hat to go search for additional data that will help them shed new light on the problem and facilitate its solution. They can switch to the yellow hat thinking to encourage their peers as they see a lot of good that could flow from completing the project satisfactorily, in spite of the difficulties that their black hat revealed.

Having the hats coloured differently helps students to understand that in critical thinking and problem solving, there usually is no one-way to solve a problem. And that if one approach does not appear to derive a solution, they should be prepared to try other approaches that help to advance their thinking and problem solving.

The variety of coloured hats is a simple and convenient way to teach students that they should be prepared to try alternative approaches to problem solving but it is important to also point out that in the normal course of thinking, it is quite common to utilize several coloured hats simultaneously. Besides, even though the hats have been described and discussed alphabetically in this paper for convenience, it is worth pointing out to students that there is no set sequence in which the hats are always to be worn. It depends on the nature of the problem that is being solved. For example, one problem might require a basic explanation (white hat thinking) before any steps to its solution can be attempted. Another search for a solution might be started by a motivational speaker who convinces shareholders of a very promising investment alternative (yellow hat thinking). Yet another one might start with what is called a SWOT analysis showing the Strengths (blue hat), Weaknesses (black hat) Opportunities (yellow hat), and Threats (black hat).

Whether De Bono's Six Thinking Hats are used one at a time, in unison or in a sequence of steps they represent a pedagogical model that can be used to effectively teach students how to think critically and engage in serious problem solving in a colourful and entertaining way. The model is not only good fun in the classroom or lecture theatre, it is also versatile so that it can be applied at every feasible level of critical thinking and problem solving ranging from very simple to highly complicated problems. The level of sophistication depends on the learning stage of students or the individuals involved in trying to solve a nominated problem. As De Bono (1992b) himself reports, "It has already been in use with six-year-olds and with senior executives in the world's largest businesses" (p. 161). Noting that it is not easy to explicitly teach critical thinking and problem solving skills, here is a model that is simple and practical enough to be made a good tool for teaching these skills in a fun-filled way and making them, as Costa and Kallick (2000) say habits of mind for our students, so they can learn them, live by them, and pass them on to other people.

In the Six Thinking Hats model, no coloured hat is prettier than another. None is more important than the other. They are all of greatly equal value. And each has potential to contribute to the understanding of a problem and to identifying how the problem can best be solved. Applying them helps students to learn that critical thinking and problem solving are indeed skills that anyone can learn. They are not the preserve of a few gifted individuals or those endowed with exceptional capacity for argumentation. Just as anyone can wear different coloured hats, so can anyone bring different perspectives to critical thinking and problem solving. To end this discussion with De Bono's (1992d) words of wisdom, if properly taught:

The hats allow full attention to be paid to the critical aspects of thinking, the constructive aspects of thinking, and the creative aspects of thinking. The hats provide a framework for learning about the different aspects of thinking and for understanding thinking. Without them, it can be difficult to teach thinking. (p. 165) 


\section{References}

Burns, A. (2000). Introduction to Research Methods (4th ed.). Frenchs Forest, NSW: Pearson Education Australia

Carmichael, K. (1997). About Critical Thinking: Letter to Olivetti. Union School District: Laguna Salada.

Costa, A. L., \& Kallick, B. (2000). Integrating and Sustaining Habits of Mind. Melbourne, VIC: Hawker Brownlow Education.

Cunningham, G. (1998). Assessment in the Classroom. London: The Falmer Press.

De Bono, E. (1956). Six Thinking Hats. Cambridge: Little, Brown and Company.

De Bono, E. (1982). Plus, Minus, Interesting: Weighing the Pros and Cons of a Decision, De Bono’s Thinking Course. http://www.mindtools.com/pages/article/newTED_05.htm

De Bono, E. (1985). Six Thinking Hats. London: Penguin Books.

De Bono, E. (1992a). Six Thinking Hats for Schools: Resource Book 1. Melbourne, VIC: Hawker Brownlow Education.

De Bono, E. (1992b). Six Thinking Hats for Schools: Resource Book 2. Melbourne, VIC: Hawker Brownlow Education.

De Bono, E. (1992c). Six Thinking Hats for Schools: Resource Book 3. Melbourne, VIC: Hawker Brownlow Education.

De Bono, E. (1992d). Six Thinking Hats for Schools: Resource Book 4. Melbourne, VIC: Hawker Brownlow Education.

De Bono, E. (1995). Serious Creativity. The Journal for Quality and Participation, 18, 12-18.

Dewey, J. (1910). How We Think. Lexington, MA: Heath and Co.

Dewey, J. (1933). How We Think: A Restatement of the Relation of Reflective Thinking to the Educative Process. New York: Heath and Co.

Dobozy, O., Bryer, B., \& Smith, R. (2012). Educational Psychology. Milton: John Wiley.

Drucker, P. F. (1954). The Pratice of Management. Sydney: Harper Collis.

Esterle, J., \& Cluman, D. (1993). Conversations with Critical Thinkers. San Francisco, CA: Whitman Institute.

Facione, P. A. (2011). Measured Reasons and Critical Thinking. Lillbrae, CA: The California Academic Press.

Hill, J. (1981). Measurement and Evaluation in the Classroom. Columbus, OH: Merrill.

Killen, R. (2013). Effective Teaching Strategies: Lessons from Research and Practice (6th ed.). Melbourne: Cengage Learning.

Kivunja, C. (2014). Do You Want Your Students to Be Job-Ready with 21st Century Skills? Change Pedagogies: A Pedagogical Paradigm Shift from Vygotskyian Social Constructivism to Critical Thinking, Problem Solving and Siemens’ Digital Connectivism. International Journal of Higher Education, 3, 81-91. http://dx.doi.org/10.5430/ijhe.v3n3p81

Kivunja, C. (2015a). Teaching, Learning and Assessment: Steps towards Creative Practice. Melbourne: Oxford University Press. (In Press)

Kivunja, C. (2015b). Exploring the Pedagogical Meaning and Implications of the 4Cs 'Super Skills' for the 21st Century through Bruner's 5E Lenses of Knowledge Construction to Improve Pedagogies of the New Learning Paradigm. International Journal of Creative Education, 6, 1-19.

Larrivee, B. (2008). Development of a Tool to Assess Teachers' Level of Reflective Practice. Reflective Practice, 9, 341360. http://dx.doi.org/10.1080/14623940802207451

Le Cornu, A. (2009). Meaning, Internalization and Externalizations: Towards a Fuller Understanding of the Process of Reflection and Its Role in the Construction of the Self. Adult Education Quarterly, 59, 279-297.

http://dx.doi.org/10.1177/0741713609331478

Martinez, J., \& Martinez, N. C. (1999). Teacher Effectiveness and Learning for Mastery. The Journal of Educational Research, 92, 279-285. http://dx.doi.org/10.1080/00220679909597607

Miller, S. (1990). Critical Thinking in Classroom Discussion of Texts: An Ethnographic Perspective. The Annual Meeting of the American Educational Research Association, ERIC Document Reproduction Service No. ED320886, Boston, 9 April 1990, 67-81.

Mulnix, J. W. (2010). Thinking Critically about Critical Thinking. Educational Philosophy and Theory, 10, 471-482.

NCECT (2014). The Critical Thinking Community: Defining Critical Thinking. The National Council for Excellence in Critical Thinking. http://www.criticalthinking.org/pages/defining-critical-thinking/766

Petty, G. (2009). Teaching Today: A Practical Guide (4th ed.). Cheltenham: Nelson Thornes Ltd.

Pohl, M. (1997). Teaching Thinking Skills in the Primary Years: A Whole School Approach. Melbourne: Hawker Brownlow Education. 
Reynolds, M. (2012). Critical Thinking and Systems Thinking: Towards a Critical Theory for Systems Thinking Practice. 8th HSSS National and International Conference: Systems Approach to Strategic Management, Thessaloniki, 5-7 July 2012, 7-12.

Tapscott, D. (2009). Grown Up Digital: How the Net Generation Is Changing Your World. New York: McGraw-Hill. Trilling, B., \& Fadel, C. (2009). 21st Century Skills: Learning for Life in Our Times. San Francisco, CA: Jossey-Bass. 